\title{
Part II.-Reviews.
}

Sammlung Kleiner Schriften zur Neurosenlehre (Collection of Short Contributions to the Doctrine of the Neuroses). Fourth series. By S. Freud. Leipzig and Vienna : Heller \& Co., 1918. Pp. 717.

The contest between the champions and the opponents of psychoanalysis apparently shows no signs of abating, although it may well be that the last word will not lie with the extremists on either side. In the meanwhile, without waiting for that harmonious solution, it cannot be too often repeated that even those who have no intention and no wish to become psycho-analysts cannot afford to neglect altogether to obtain some direct knowledge of the work of the man who-whatever may be thought of some of his present or former disciples-remains the powerful originator of a highly remarkable revolutionary movement in both morbid and normal psychology. 'To the end of such knowledge none of Freud's writings are so well adapted as the successive volumes published under the above title. They are short, they are highly varied, they frequently deal with fundamental problems, they are at times interestingly personal, and they may usually be grasped without too severe an intellectual effort. This latest series, a very substantial volume, contains no fewer than thirty-two studies, dating from the years I 912 to 1918.

There are some for all tastes, though a few will only appeal to the most specialised psycho-analyst. IVe find, for instance, "The Disposition to Compulsive Neurosis," "A Case of Paranoia contradicting the Psycho-analytic Theory," "The Transposition of Impulses in Anal Eroticism," "False Reminiscence in Psycho-analytic Work," "The Conception of the Unconscious," "Fairy Tales in Dreams," "Mythological Parallels to an Obsessional Idea," three "Contributions to the Psychology of the Love-life," "Grief and Melancholia," six papers on "The Technique of Psycho-analysis," "The Motive of the Casket Choice," "On War and Death," "A Childhood Recollection in Goethe's "Dichtung und Wahrheit," and so on, the final paper-the only detailed case brought forward in the volume-being the "History of an Infantile Neurosis," covering forty pages, here first published and put forward as a fragmentary by-product in the psycho-analytic investigation of an adult case.

It is impossible here to touch on all of these papers, but a few may be specially mentioned. The first, on the history of the psychoanalytic movement, the growth of Freud's doctrines and his relations to Adler and Jung, is, from the personal point of view, much the most interesting in the volume; it was epitomised in this Journal when first published in 1914. The second study is a valuable and comprehensive discussion of narcissism and of the large place it has gradually acquired in the psycho-analytic scheme, from being, before Freud adopted it, simply an auto-erotic perversion, in which the subject treated his own body as an object of sexual interest and admiration, until it has finally become regarded in the psycho-analytic system as a normal stage in the orderly sexual development of human beings generally, "no longer a perversion, but the libidinous complement to 
the egoism of the self-maintaining impulse which is the proper inheritance of every living creature." The justification of the wider application of narcissism was first found in the need for a psycho-analytic explanation of dementia præcox (paraphrenia in Freud's terminology). Megalomania and aversion of interest from the outer world being taken as fundamental traits of the paraphrenic, narcissism is regarded as expressing the new aims and satisfaction of those impulses. It is further argued that both among primitive peoples and among children various traits may be noted which are to be considered an expression of narcissism, which is viewed as distinct from auto-erotism, representing a further stage of development, though the exact mode of defining the difference is regarded by Freud as a difficult and delicate problem. $\mathrm{He}$ points out two roads, however, by which he considers that the knowledge of narcissism may be increased: (I) the study of hypochondria, and (2) the consideration of the love-life of the sexes. Freud finds "a fragment of hypochondria in all neuroses," and associates it with a hypersensitive erogeneity which may be paralleled with narcissism. The consideration of the normal sex-life leads to a more definite approach to narcissism. There are two types of sexual attraction-that which is based on the relation of the child to its mother or her protecting and nourishing substitute, by Freud termed the leaning-type, and the more perverted and often homosexual type, which finds its primary object, not in the mother, but in its own person. "It is in this observation that we find the strongest of the motives which compel us to accept narcissism." We have thus to recognise that there are two primary sexual objectsthe person himself and the protecting woman-and we must accept the possible primary narcissism of any individual, perhaps to become eventually dominant in his object-choice. There is a difference, however, to be recognised between men and women. While the boy at puberty tends to transfer his primary over-valuation of self to his sexual object, the girl at puberty, with the development of the latent sexual organs, more frequently and perhaps in the most genuinely feminine type shows an increase of the original narcissism, "with a self-satisfaction in her bearing which compensates for her impaired freedom in object-choice." Such women love themselves with the same intensity that men love them; they do not wish to love but to be loved, and the man who fulfils this condition is the man who pleases them. They are often highly attractive to men. But at the same time much of the dissatisfaction of men in love, their doubts, their complaints over the riddle of women, are caused by this feminine narcissism. There are women, however, Freud adds, who love in the masculine way, and, moreover, women are often delivered from narcissism by the child which, being a part of their own bodies, is fitted to become an object of love by natural transition.

The theme may be said to be continued in a later series of "Contributions to the Psychology of the Love-life." In the first of these a special type of sexual choice in men is investigated. The man of this type is impelled to make three demands as a condition for loving: (1) there must be an injured third party-lover, husband, or friend; (2) the beloved must not be pure and virginal, but approximate to the courtesan and be always an object of jealousy; (3) he must be able to 
exercise an impulse to "save" her. This attitude is regarded as due to infantile fixation of tenderness on the mother, even the desired courtesan element being traced to the child's discovery that his mother has led that physical sex-life which he has been taught to look upon as low. The next chapter deals with psychic impotence, which Freud regards as so common as to be almost a trait of our civilisation. He connects it with "incestuous" fixation of affection in childhood on the mother or sister, arrest of development and consequent disharmony of the tender and sensual factors of love, leading to a tendency for the love impulse to go out towards inferior objects. The chapter concludes with reflections on the possibility that a high culture is unfavourable to the proper development of the love-life, and it is pointed out that the emotion in women corresponding to psychic impotence is the demand for the stimulus of the forbidden. The next chapter, which has an anthropological colouring, deals with the taboo of virginity, on the tendency among various people to assign to some other person than the husband the first intercourse with the wife. Freud considers that there really is a psychological ground for this custom, and that a resistance to the sexual life in the woman has to be overcome; there is not only the dread of pain but the opposition offered by her narcissism to be overcome, so that sex relations are apt at first to be for her a bitter deception. The husband, therefore, was wise who assigned to a priest or other functionary the duty of overcoming and diverting these reactions, which might otherwise have brought unhappiness on himself.

Turning from normal psychology to psycho-pathology, we may note a study of "Grief and Melancholia." Just as the dream presents the normal prototype of narcissistic psychic disturbances, so, Freud argues, we may attempt to illuminate the nature of melancholia by comparing it with normal grief. In grief it is the world which, by the loss of some beloved object, has become poor and empty ; in melancholia the loss is felt as having taken place in the ego itself, which seems to have become unworthy. But if we listen patiently to the manifold self-accusations of the melancholic, we cannot escape the impression that they often do not fit the patient's own person, but with a little modification quite fairly fit some person whom he loves, has loved, or ought to love. Investigation confirms this impression. So we have in our hands the key to the picture presented by the disorder : the self-accusations are reproaches really directed to the object and turned against the patient's own ego. The wife who loudly bewails the fate of her husband bound to so unworthy a mate is really accusing her husband of unworthiness, whatever may be its form. The process can be reconstructed. There was a choice of object; love was bound up with a particular person; by the influence of some mortification or disillusion the object of love is shattered. The normal result, the transfer of love to some other object, fails to follow, and the libido withdraws into the ego. There an identification takes place with the abandoned object, and the ego is judged as that object is judged. So that instead of, as in grief, a loss in the object, there is a loss in the ego. It would seem, Freud remarks in agreement with Rank, that the object-choice originally took place on a narcissistic foundation, so that when the shock of deception comes, there is a regression to narcissism, 
and the love-relation with the beloved object, in spite of the conflict, still subsists in a new form. Identification is the preliminary stage of object-choice and in its expression is ambivalent. There is a desire to incorporate the beloved object, in the oral and cannibalistic phase, in a way corresponding to eating; Freud agrees with Abraham that thus must be explained the melancholic's refusal of food. The love-adaptation of the melancholic to its object has, however, experienced a two-fold fate: it has partly regressed to identification, but it has also partly returned, under the influence of an ambivalent conflict, to the stage of sadism. It is this sadism which explains the tendency of the melancholic to suicide. "The analysis of melancholia teaches us that the ego can only kill itself when by the return of the object-adaptation on to itself it regards itself as an object, and so can direct its hostility against itself." The most remarkable trait of melancholia is its tendency to develop into mania, so that the analytic explanation of melancholia must cover mania. That, Freud admits, is not quite easy to effect. He cannot go beyond " a first orientation." When one has succeeded by one stroke in releasing oneself from some long-continued pressure there is a feeling of triumph. Mania is just such a triumph, only the ego is unaware of what it has conquered and why it triumphs. The manic person is demonstrating to us his freedom from the object which has caused his suffering. This part of the explanation Freud regards as not more than " plausible," but the whole paper is a brilliant example of his virtuosity in devising a dynamic mechanism for psycho-pathological states.

Some sections of the volume will appeal chiefly to the specialist psycho-analytic reader. This is the case, for instance, with two papers which form part of "Prolegomena to a Metapsychology," meant to clarify and deepen the theoretical assumptions beneath the psychoanalytic system. These papers are highly vague and abstract; they make much play with the "polarities" and "ambivalencies" which pleased the old German metaphysicians, and to many readers it will probably seem, indeed, that (to parody Milton) the new metapsychology is but the old metaphysics writ large. Freud himself seems to have had a suspicion of this, for he has abandoned his original intention of developing these papers into a volume. Other papers that appeal to the specialist are the series of "Further Counsels on Technique." There is here, however, much wise advice which may be appreciated by many who are not psycho-analysts.

A paper that stands by itself is entitled "Reflections on War and Death" (it has been translated by Dr. Brill, and published in a small volume by Moffat, Yard \& Co., of New York). Written in the midst of the great conflict, it is a thoughtful discussion in a large though psycho-analytic spirit of some of the problems raised by the war. There is an absence throughout of any harsh, bitter or contemptuous reference to the enemies of the author's country. He retains his racial internationalism (as it may be) unimpaired.

It has only been possible to touch on a few of the rich contents of this large volume. The portions of the volume which remain are of at least equal interest and value alike to the psychologist and the psychopathologist. 
Sammlung Kleiner Schriften zur Neurosenlehre (Collection of Short Contributions to the Doctrine of the Neuroses): Fourth series. By S. Freud. Leipzig and Vienna: Heller \& Co., 1918. Pp. 717

Havelock Ellis BJP 1920, 66:453-456.

Access the most recent version at DOI: 10.1192/bjp.66.275.453

References

Reprints/ permissions

You can respond to this article at

Downloaded from
This article cites 0 articles, 0 of which you can access for free at: http://bjp.rcpsych.org/content/66/275/453.citation\#BIBL

To obtain reprints or permission to reproduce material from this paper, please write to permissions@rcpsych.ac.uk

/letters/submit/bjprcpsych;66/275/453

http://bjp.rcpsych.org/ on October 19, 2017

Published by The Royal College of Psychiatrists

To subscribe to The British Journal of Psychiatry go to: http://bjp.rcpsych.org/site/subscriptions/ 